\title{
Cloud based Electric Vehicle Load Management at DC Charging Stations
}

\author{
Victor George, Pradipkumar Dixit, Madhuri. A, Sayantani Gupta, Vismayi. V
}

\begin{abstract}
DC distribution system is getting wider acceptance around the world due to the reduction of conversion stages between $A C$ and $D C$ and the increased popularity of DC loads. Solar PV is a genuine source of DC which can directly power the $D C$ loads like electric vehicle $(E V)$ battery for charging. Increased deployment of Electric vehicles need more charging stations, preferably powered with renewable DC sources or DC microgrid. The intermittent nature of solar power necessitates a backup support from the AC grid. An attempt is made to develop a load management system at a DC charging station powered from renewable sources. The proposed load management system can manage the various DC loads at the charging station based on the power rating of the charging equipment, available solar power and the availability of the backup $A C$ grid. The entire system is automated and enabled with IoT in order to receive the available solar power data through a cloud based communication system. Identification of grid failure, instantaneous load changes and communication infrastructure through cloud for updating the generation profiles are the key concerns of the proposed system.
\end{abstract}

Keywords : Charging stations, DC loads, DC microgrid, grid failure,IoT, load management.

\section{INTRODUCTION}

\section{$\mathrm{P}$} opularity of DC loads depends on the availability of DC distribution system as well as DC microgrid especially with the renewable generators. Electric vehicles (EVs) are genuine DC loads and their promotion schemes around the globe are motivated by the carbon reduction paradigm. To satisfy this intention, EV charging stations should be free from non-renewable energy sources as far as possible. DC microgrid, mainly powered from solar $\mathrm{pv}$ will be an excellent alternative to the conventional AC grid for powering EV charging stations. The intermittent nature of the solar power and the dynamic load changes at the charging stations necessitate the grid power as a backup at the charging stations. But identification of the grid failure is crucial in such a scenario in order to manage the loads at the charging stations with available microgrid power, especially battery storage is less preferred.

Revised Manuscript Received on March 5, 2020.

* Correspondence Author

Victor George*, Electrical and Electroncs department,M.S Ramaiah Institute of Technology, Bengaluru, India. Email: victor.georgevg75@gmail.com

Pradipkumar Dixit, Electrical and Electroncs department, M.S Ramaiah Institute of Technology, Bengaluru, India. Email:dix.hve@gmail.com

Madhuri. A, Electrical and Electroncs department, M.S Ramaiah Institute of Technology, Bengaluru, India. Email: makelectric95@gmail.com

Sayantani. Gupta, Electrical and Electroncs department, M.S Ramaiah Institute of Technology, Bengaluru, India. Email: guptasayantani94@gmail.com

Vismayi. V, Electrical and Electroncs department, M.S Ramaiah Institute of Technology, Bengaluru, India. Email: anu.visu.98@gmail.com.
A successful microgrid must have intelligent methods to manage and control its loads according to the availability of the source power. Intermittent nature of solar power can create uncertainty at the EV charging stations driven from solar pv. Energy sources have finite capacity and if overloaded, willseverely distort the voltage output or completely shut the system down [1]. Modern distribution system has a comparable amount of DC loads. DC loads can be directly powered with DC sources, especially with solar pv generators and thus can be reduce losses in the converter stages. The excess power required by the DC loads can be met by the AC grid. If the AC grid is not available, then the dc loads can be managed by a prioritization scheme according to the available solar power. The main concern is the utilization of available solar power in feeding the critical loads according to their priority. In the absence of both $\mathrm{AC}$ grid and DC microgrid power, the system will fail.

A low voltage DC (LVDC) distribution system is a relatively new concept in the field of electricity distribution. The benefits of LVDC distribution system enable it to have many targets of applications [2]-[4]. Interconnecting DC based agents such as solar pv, DC loads, battery storage through a DC power system avoid unnecessary power conversions stages. Electric vehicles (EVs) are getting more attention across the world in recent years. The sufficient deployment of charging stations is the need of the hour. EV charging stations are reported to have more smart features in the latest research studies [5]-[7]. Necessity of public charging stations compared to the residential charging is well explained in [8]. Waiting time at the charging station can be reduced by smart communication between electric vehicles and the charging stations [5]. Prioritization at the public charging stations needs special attention. Registered time and the state of charge levels are the two criteria considered in [6] for setting the priority. A different situation may arise if the DC charging station is primarily driven by solar pv generators, as they are generating DC power directly, is supported by the AC grid for backup purpose. In such a situation the availability of the AC source and the intermittent nature of solar power are the crucial factors that determine the priority scheme. If the charging station is considered as a hybrid microgrid the identification of availability of the supporting AC grid can be considered as islanding detection. A review of islanding detection techniques is reported in [9].

A cloud based communication between charging stations and the microgrid can be used to identify the available solar power at any point of time in deciding the critical loads that can continue in the system even if the AC support is lost. Solar generation forecasting methods are reviewed in [10]. 
Various issues in the cloud based communication infrastructure in power system sector are getting attention in recent years [11], [12]. Every charging station may have different chargers present according to various standards and schemes in which voltage levels and power ratings are different. Energy flow from each charging equipment may differ according to the state of charge (SoC) of the Electric Vehicle (EV) battery [13] and the mode of charging scheme used. Hence the energy flow from the charging equipments should be managed based on the available energy at the charging station. Standardization of charging scheme and EV battery are the two critical issues to be sorted with immediate attention. Protection is an important concern to be addressed in a DC microgrid based EV charging station [14]. Future distribution networks are likely to be data driven. Importance of cloud based communication for digitally controllable converters used at the DC charging stations are discussed in [15]. Available renewable energy has to be utilized effectively at the DC charging stations. Role of data driven energy management with wireless on-road charging stations is introduced in [16] proposes transfer of excess renewable energy to the battery swapping stations and on-road charging system rather than storing in bulk battery storage at the charging stations. The major consideration of the proposed work is to cut down the charging equipments available at a charging station according to the solar power available to the charging station when AC grid power is absent. This information will be critical in case of a smart charging station where the communication between the EV users and the charging station is crucial in guiding the EV to the most suitable charging station.

A cloud based load management is proposed for the EV charging stations. More hardware testing is needed to identify the practical issues in communicating the available energy profiles with that of probable load at the charging stations. Hence an attempt is made to establish a cloud based communication infrastructure between the generation data and the charging station thereby managing the loads autonomously in accordance with the available solar power in the absence of supporting AC grid power. Cloud based communication infrastructure can be utilized for the efficient coordination between EV users and charging centers. Hardware details of the proposed system is explained in the following sections.

\section{STRUCTURE OF THE PROPOSED SYSTEM}

\section{A. General Structure of the charging station}

The proposed model consists of a DC microgrid consists two distributed generators supplying the DC loads (EV battery) in the autonomous mode. A general structure of such an arrangement is shown in Fig.1. The different voltage level present indicates the different charging schemes like CHAdeMO, Bharat DC etc. The voltage level and the power capacity can be different in different charging schemes. The distributed generators (DG) shown can be solar pv generators that can be directly connected to the DC bus through DC/DC converters. The AC grid is connected through an AC/DC converter.

When the load required exceeds the available generation profiles, the excess power is taken from the AC grid. In such a condition if the AC grid is not available, then the power available is supplied to the critical loads (different charging equipments) and the other loads in order of priority. Criticality can be flexibly set prior to the operation based on charging schemes like fast charging where large amount of power is getting transferred in short span of time or the vehicle is having least amount of state of charge etc. Priorities can be assigned dynamically based on the SoC of the EV battery or the time of entry to the charging station etc. In either case the proposed system will able to manage the loads automatically in whatever way the priority is assigned.

\section{B. Methodologies used}

The various load power and voltage levels shown in Table. I represent the different charging schemes used at the charging station. The priority assigned to the developed modelis also shown. DC fast charging requires higher power. Four different power levels are used in the experiment.

The load management algorithm should work when the unavailability of the AC grid is detected. Different methods were reported in literature for islanding detection like active, passive and hybrid. The selected approach for the purpose of islanding detection is OUF/OUV method. It is a passive detection method. Voltage based detection is based on the power mismatch prior to an islanding condition in which an under-voltage or over-voltage condition could result in an islanded system. Frequency-based detection schemes are widely used for islanding detection. Frequency increases if generation exceeds load and it decreases when load exceeds generation. Frequency deviations from nominal and $\frac{d f}{d t}$ aregood indicators of an islanding condition. Both of themethods when used individually may lead to a large Non-Detection Zone (NDZ). But, when both the methods are used together, the NDZ reduces substantially. The basic requirements for the selected method are that the peakdetector circuit to detect any transients in the voltage and zero crossing detector circuit to detect any fluctuations in the frequency. In case both or any of the above conditions are met, a signal is given for the relay to trip and disconnect the ac grid as well as the load management system to start functioning immediately.

The peak detector circuit is used to monitor if the input ac waveform is within the voltage sag and swell limits. The AC grid is disconnected when it crosses these limits. As per IEEE 519 standard, the voltage sag-swell limits are within $10 \%$ of the nominal value i.e. 230 Volts with a tolerance of $10 \%$. Hence, the upper limit of the input ac voltage waveform comes to 207 Volts and the lower limit is 253 Volts. The zero crossingdetectorcircuitisused to 


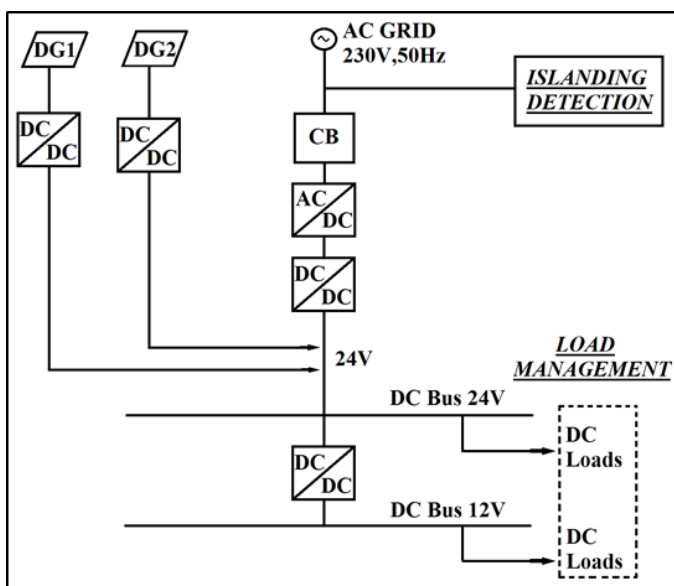

Fig. 1. General structure of DC bus

Table- I: DC loads involved in the proposed system

\begin{tabular}{|l|l|l|l|}
\hline $\begin{array}{l}\text { Load } \\
\text { number }\end{array}$ & Voltage(V) & Watts(W) & $\begin{array}{l}\text { Order of assigned } \\
\text { priority }\end{array}$ \\
\hline L1 & 12 & 5 & I \\
\hline L2 & 12 & 22 & II \\
\hline L3 & 12 & 9 & III \\
\hline L4 & 24 & 42 & IV \\
\hline
\end{tabular}

monitor any fluctuations in the input ac waveform. As per the EN 50160/2006 standard, the over-under frequency limits are $50 \mathrm{~Hz}$. with a tolerance of $2 \%$. The lower limit hence comes to $49 \mathrm{~Hz}$. and the upper limit to $51 \mathrm{~Hz}$.

The two processors used are Arduino UNO and Arduino MEGA2560. The switching circuitry is realized using solid state relays since it is required to control a high power application using a low power relay.

A separate $0-25 \mathrm{~V}$, voltage sensor is used for the voltage sensing. A potential divider is used to adjust the voltage in the range of 0-5 Volts which the Arduino is able to sense it appropriately. The ACS712 current sensors are used to measure the current. The available solar power is assumed in the proposed work which is made accessible to the load management system through a Firebase cloud platform.

\section{HARDWARE IMPLEMENTATION OF THE LOAD MANAGEMENT SYSTEM}

The hardware implementation of the load management system consists of two parts namely islanding detection part and the load management part. Islanding detection is done based on peak detector and zero crossing detector circuits. Coding for both is done with the help of Arduino UNO. The voltage tapped from the AC grid is stepped down using a $230 / 6 \mathrm{~V}$ transformer which is given as the input to the peak detector and zero crossing detector circuits.

The peak detector circuit shown in Fig.2 outputs the peak voltage of the input. The capacitor stores the current peak voltage. If the input voltage is larger, the op-amp output goes positive until the capacitor is charged up to the new peak value. If the input voltage is smaller, the diode keeps the capacitor from being discharged. The output of the peak detector circuit is given to a dc voltage sensor.

The circuit was simulated using the NI Multisim software which is shown in Fig.3. The simulation result of the peak detector circuit is as shown in the Fig. 4. It can be observed that the peak of the input ac voltage waveform is detected. The voltage sensor senses the peak voltage of the input waveform and in case if the value exceeds the sag or swell limits, the relay connected to the microcontroller trips and disconnects the AC grid. Since 230 Volts AC waveform cannot be directly given to the Op-Amp circuit, it is stepped down to 6 Volts using a step-down transformer and then given to the peak detector circuit. The sag and swell limits have changed accordingly. In order to reduce the ripples in the output of the peak detector circuit the time constant calculation is done as follows.

$C R_{L}>15 \mathrm{~T}$

$C R_{L}>\frac{15}{50}$, and Let $\mathrm{C}=100 \mathrm{uF}$ so that $\mathrm{R}_{\mathrm{L}} \cong 3.3 \mathrm{k} \Omega$.

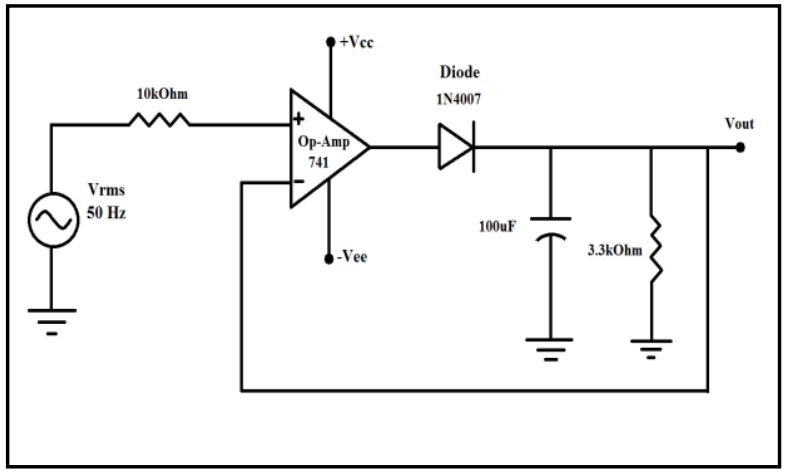

Fig. 2. Peak detector circuit

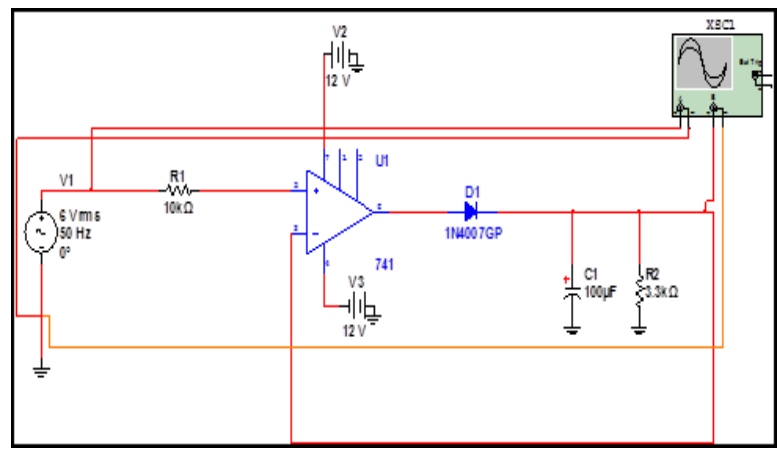

Fig. 3.Peak Detector Simulation Circuit

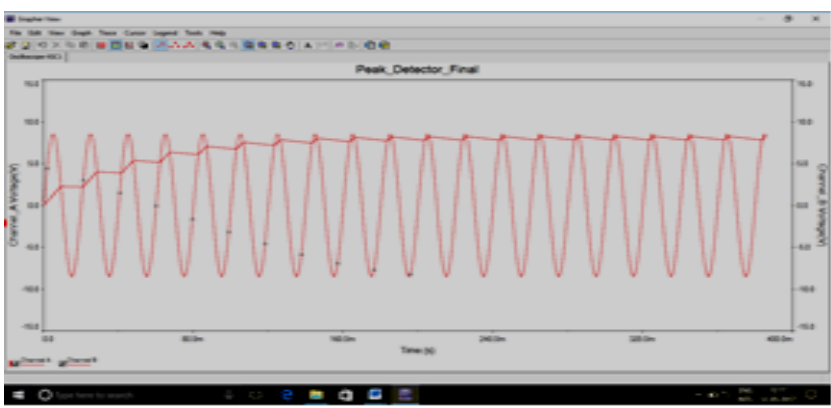

Fig.4. Result of peak detector circuit simulation

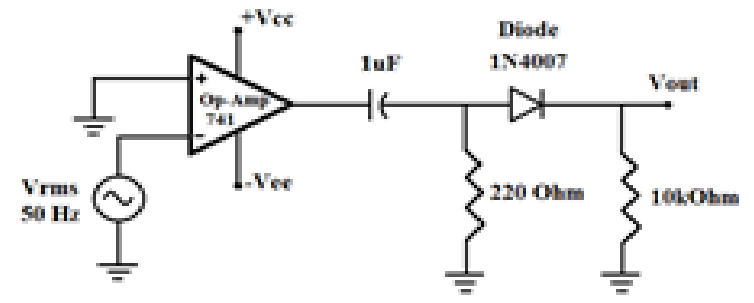

Fig. 5.Zero crossing detector circuit 


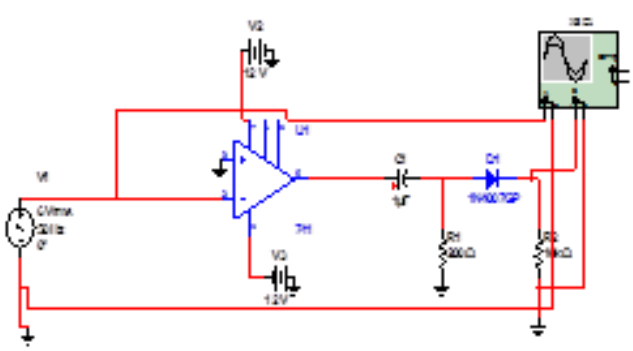

Fig. 6 simulation circuit of zero crossing detector

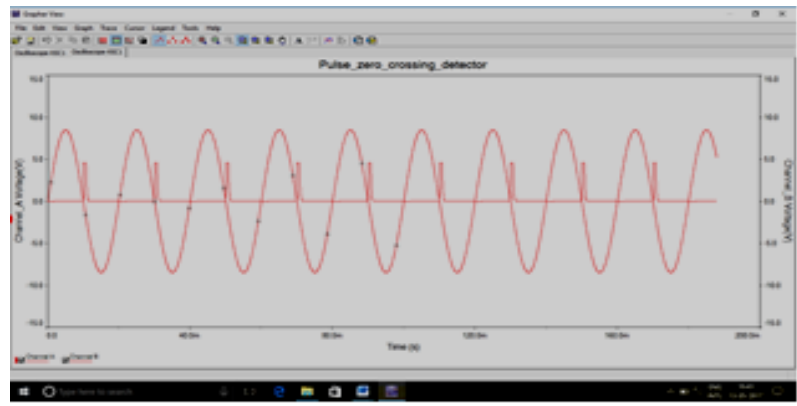

Fig.7. Simulation result of. zero crossing detector circuit

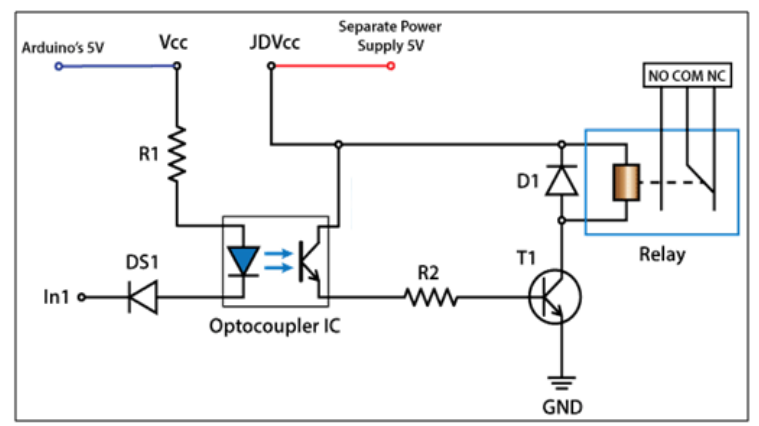

Fig.8. Processor relay interfacing

The zero-crossing detector produces pulses at each zero crossing of the input waveform. Hence, from these pulses, the frequency of the input waveform can be easily calculated. The output pulses are given to the interrupt pin of the microcontroller to calculate the frequency of the wave.

The output pulses are given to the interrupt pin of the microcontroller to calculate the frequency of the wave. In case if the frequency exceeds the limits then the relay trips and disconnects the main $\mathrm{AC}$ grid. The circuit for the zero-crossing detector is shown in the Fig.5 and the simulation circuit is shown in Fig.6. Simulation result is shown in Fig.7. It is observed from the Fig.7 that pulses are produced at every positive zero crossing of the input AC voltage waveform.

All the loads are connected to the Arduino using the relays in parallel. Depending on the priority of the loads during load management, the loads can be disconnected if the relay is triggered. The parallel connection of loads allows easy control of each load independently which results in fast switching. Since, every load is connected independently to a unique relay, failure of any one relay, affects the switching of only the appliance, associated with it. Switching of other relays does not get affected, thus reducing the maintenance. Also, detection and replacement of faulty relays can be done easily without hassle.

Fig. 8 shows the processor relay interfacing circuit. When a 0 Volts output is obtained from the processor, current $I_{2}$ flows through the resistor $\mathrm{R}_{2}$. This resistor limits the amount of current flowing into the base of the transistor. The current $\mathrm{I}_{2}$, hence, turns ON the transistor. The transistor connects one end of the electromagnet inside the relay to ground (the other end is already connected to 5 Volts), and a current of about 0.7 Amps flows. The electromagnet pulls the switch contact inside and moves it to connect the COM terminal to the NO (Normally Open) terminal. The diode across the electromagnet conducts in the reverse direction when the transistor is turned OFF to protect against a voltage spike. A load is connected across the $\mathrm{NC}$ and COMMON of the relay which gets operated when the relay gets energised.

The cloud platform used is Firebase, Google's cloud platform. It has two different storage i.e., cloud firestore and real-time database. Firebase's real time database is used to store different values from the sensors. The available power data is sent to the cloud through a Wi-Fi controller NodeMCU and then retrieved from the cloud to the local controller of the load management system for further processing. Advantage of cloud based communication is that the real time data of multiple distributed generators (solar pv) can be synchronized and effectively used for finding the available power. The data uploaded in the cloud is shown in Fig. 9. Another advantage of including various data in the cloud infrastructure is that it can be utilized for a wider energy management scheme where the energy transfer between the charging stations can be based on the available power and expected loads at the charging stations. Figure 10 illustrates the block diagram of the entire circuitry for two loads.

The current sensor is connected in series with the load to measure the current value. The voltage sensor in a similar way is connected parallel to the load. The load is connected to the source through the relay in order to connect or disconnect the loads from the supply. This can ensure that some of the chargers will not be available if they are not assigned high priority according to the prioritisation scheme adopted.

The cloud communication infrastructure can also be used to inform the EV users those who are part of smart communication [5] with the charging stations regarding the availability of a particular type of charger. This can increase the efficiency of an energy management system in which the EVs can be guided to the appropriate charging stations through the smart communication thereby reducing the waiting time at the charging station.

\section{RESULT AND DISCUSSION}

The testing of various sections of the hardware implementation was done individually in order to check their working. The islanding detection part consists of the peak detector and the zero-crossing detector circuits. These circuits are tested individually for their working using Arduino UNO boards. The peak detector circuit was tested by connecting its output to a voltage sensor module which senses the fluctuations in the incoming voltage waveform. The output of the zero-crossing detector is given to the interrupt pin of the Arduino UNO which senses the frequency of the incoming 
AC voltage waveform and also detects fluctuations, if any.The flow chart of the entire load management algorithm is shown in Fig. 11.

If any of the above mentioned cases are detected, then a signal is sent to trip the relay in order to disconnect the AC grid and also to trigger the load management system. The LED glowing in the Fig.12 indicates the occurrence of islanding which signals the load management system. The output of the peak detector and zero crossing detector circuit as observed on the DSO screen is shown in the Fig.13 and Fig.14. respectively. The load management circuit was tested separately using four loads and found to function satisfactorily. The complete experimental setup is shown in Fig.15. The experiments are repeated satisfactorily for islanded case also. For the purpose of demonstration of the load management system in islanded mode, islanding detection circuit and load management setup consisting of four DC loads were considered.

The load power was monitored continuously and compared with the set generation values. When the load profiles exceeded the generation profiles, then the surplus power was supplied by the AC grid. Here it was demonstrated with the help of an LED. During this condition when the AC grid got disconnected then the loads were supplied power based on the order of priority of loads.

The total power consumed by all the loads is found to be approximately 78 Watts. The load management system in autonomous mode without AC grid support was checked and found working satisfactorily for the cases as shown in the Table II. It is assumed that the available solar power information is readily available from a power prediction algorithm. Depending on the power level requirement for different chargers available at the charging station the available energy is managed between the chargers.

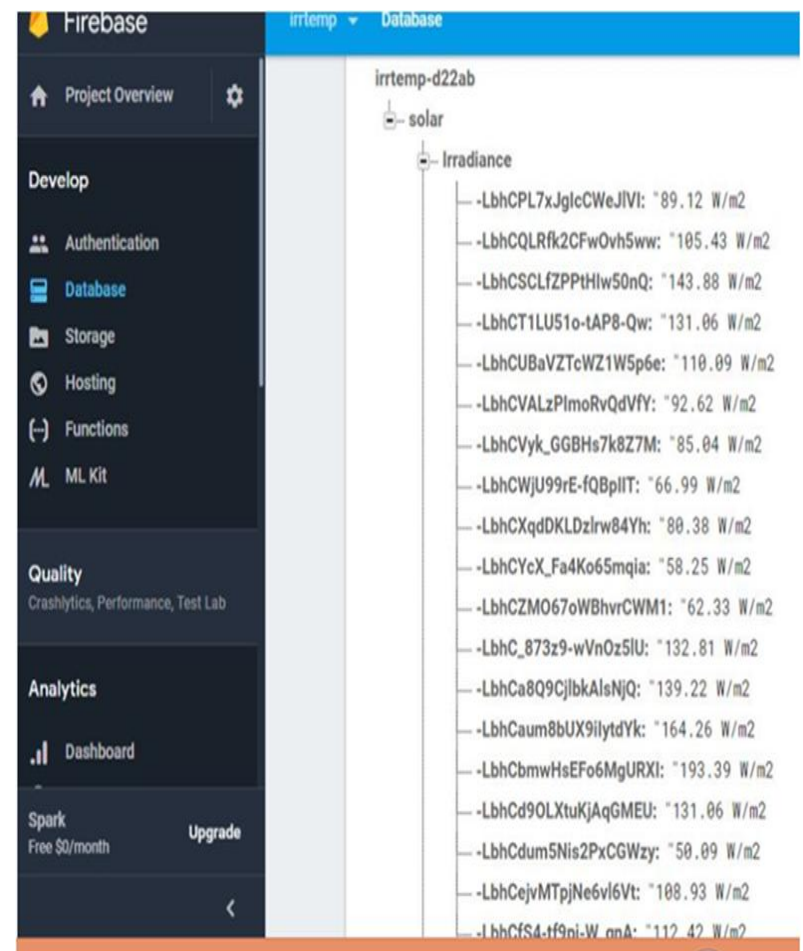

Fig. 9. Storage of various data in Firebase

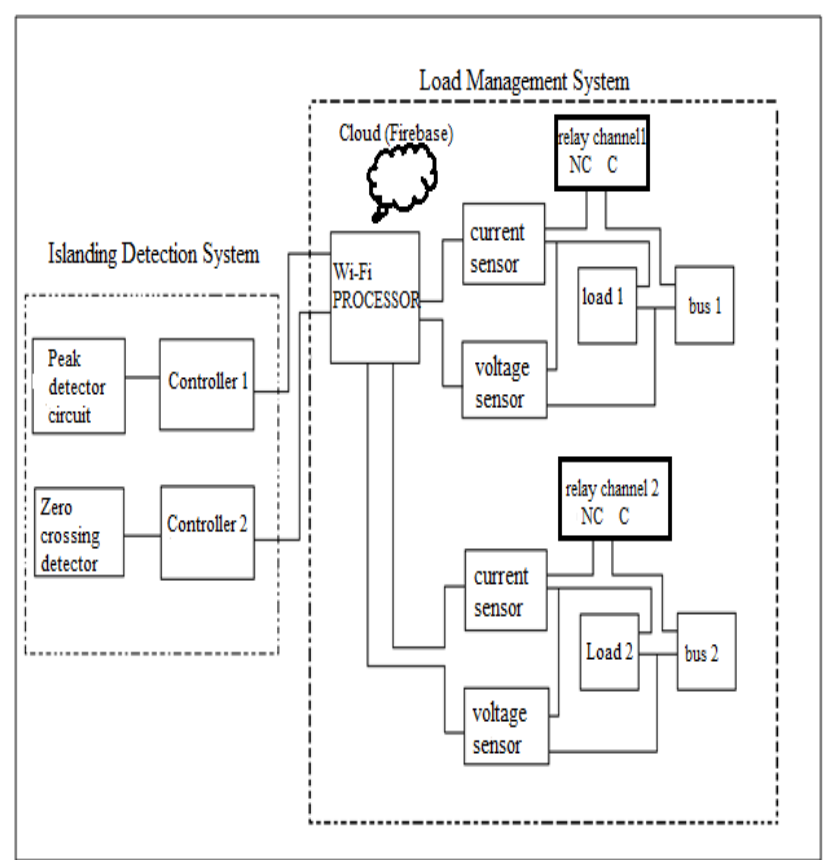

Fig.10. Block diagram of the entire circuitry

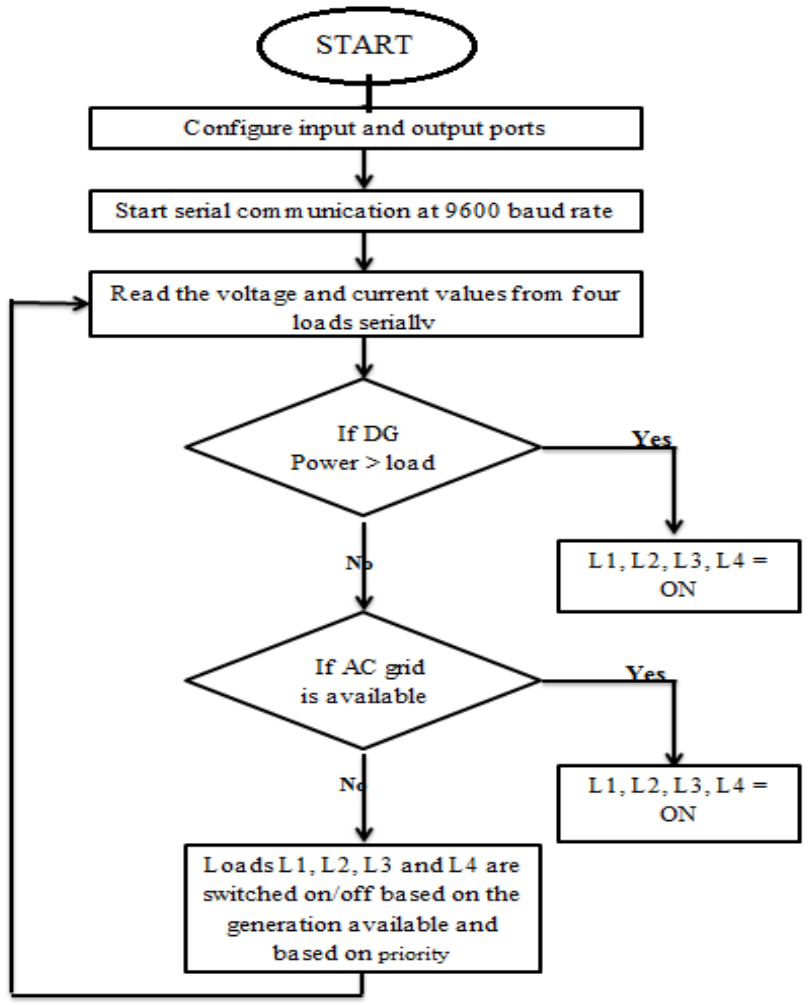

Fig.11. Flowchart for the entire load management system

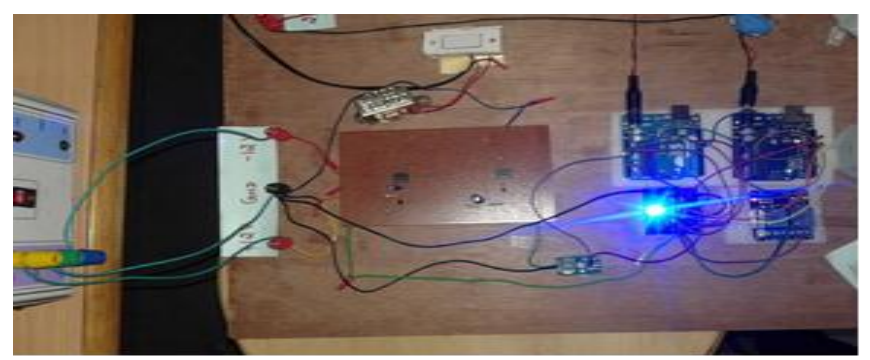

Fig.12. Indication of islanding 


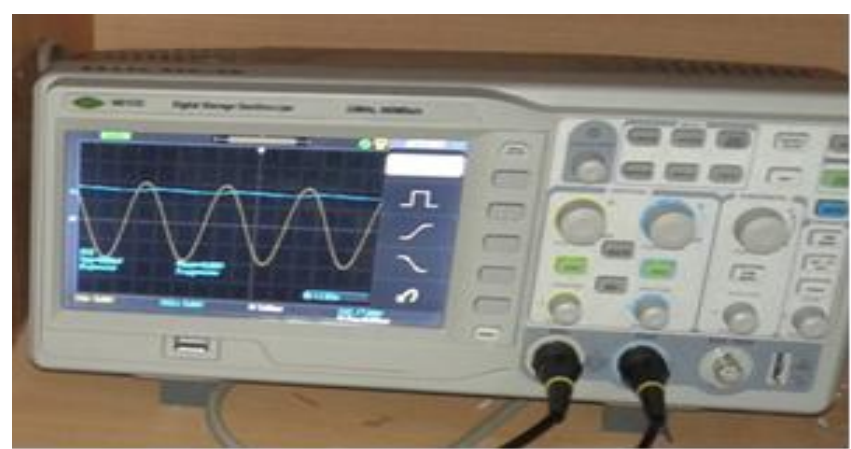

Fig.13. Output of the peak detector circuit

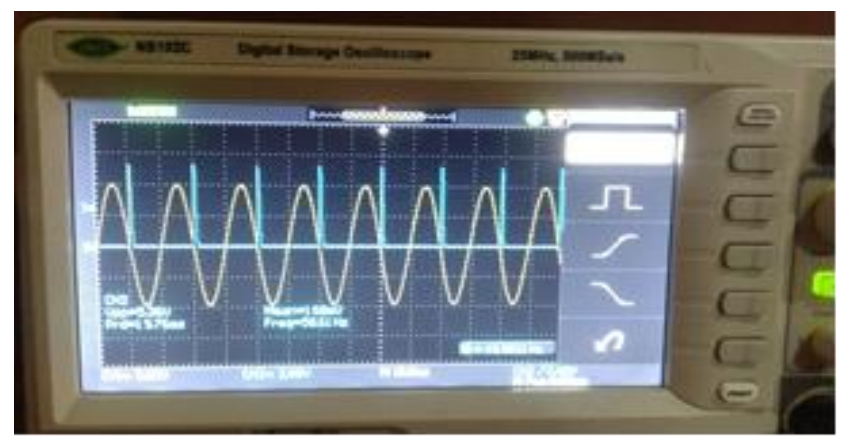

Fig.14. Output of the zero crossing circuit

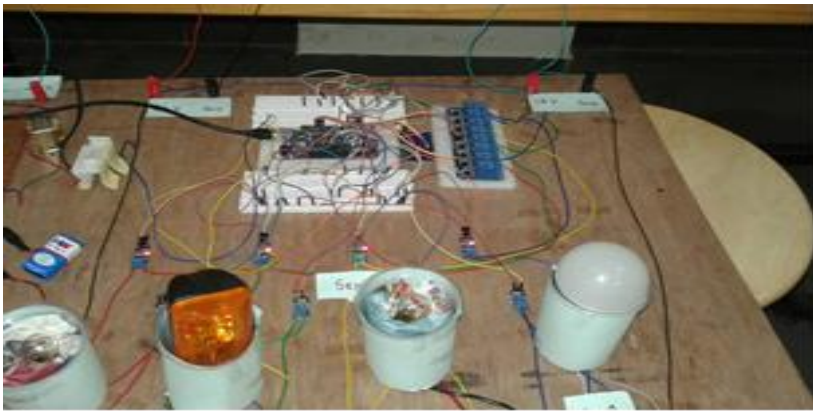

Fig. 15 Complete load management circuitry

Table II. Load shedding for various generation profiles

\begin{tabular}{|c|c|c|c|c|c|}
\hline Code sent & DG power & L1 & L2 & L3 & L4 \\
\hline None & $95 W($ Default) & ON & ON & ON & ON \\
\hline $\mathrm{q}$ & $35 \mathrm{~W}$ & ON & ON & OFF & OFF \\
\hline $\mathrm{w}$ & $20 \mathrm{~W}$ & ON & OFF & ON & OFF \\
\hline $\mathrm{e}$ & $50 \mathrm{~W}$ & ON & ON & ON & OFF \\
\hline $\mathrm{r}$ & $85 \mathrm{~W}$ & ON & ON & ON & ON \\
\hline $\mathrm{t}$ & $10 \mathrm{~W}$ & ON & OFF & OFF & OFF \\
\hline
\end{tabular}

Available DG power is taken from the cloud . (Firebase)

\section{CONCLUSION}

The developed load management system is found to be useful in managing multiple DC charging equipments powered from various DG sources at the EV charging stations according to the power availability. The proposed system will also be useful in integrating smart communication features between electric vehicles and charging stations. It can also be implemented at large scale for the effective utilization of the available DG power. The prototype loads used in the experimental setup can be considered as EV charging equipments of different power rating. The communication of the local controller with the cloud is effectively utilized in switching between the allowable loads that can be run with the available DG power.
The non-availability of ACgrid backup is successfully tested with a zero crossing detector.

Another scope for the developed system is that it can be used in signalling the smart communication between the EV user and the charging stations. The priority assignment option is flexible in such a way that the operator can assign priority to the various charging equipments at a charging station considering the SoC of the EVs coming to the station, the time they opted for the service etc. The constraint is that all the assignments should satisfy the available energy requirement. This constraint will be automatically taken care by the developed algorithm. The developed load management can be a part of the broader networks of smart charging stations in a city.

\section{REFERENCES}

1. Srinu Naik Ramavathu, Venkata Teja Datla and Harshitha Pasagadi, "Islanding Scheme and Auto Load Shedding to Protect Power System", International Journal of Computer Science and Electronics Engineering (IJCSEE), vol. 1, no. 4, 2013.

2. Pasi Salonen, Tero Kaipia, Pasi Nuutinen, Pasi Peltoniemi and Jarmo Partanen, "An LVDC Distribution System Concept", IEEE Nordic Workshop on Power and Industrial Electronics, Espoo. Jun. 2008.

3. Tero Kaipia, Pasi Salonen, Jukka Lassila and Jarmo Partanen, "Application of Low Voltage dc-distribution system - a Techno-economical Study", 19th International Conference on Electricity Distribution, Vienna, May 2007.

4. E. Rodriguez-Diaz, M. Savaghebi, J. C. Vasquez and J. M. Guerrero, "An overview of low voltage DC distribution systems for residential applications," IEEE 5th International Conference on Consumer Electronics - Berlin (ICCE-Berlin), 2015, pp. 318-322.

5. Victor George, Pradipkumar Dixit, Kunal Gaurav, Pranay Jaiswal, Aditya Swaroop, "A Novel Web-Based Real Time Communication System for PHEV Fast Charging Stations," 2018 3rd International Conference on Circuits, Control, Communication and Computing (I4C), Bangalore, India, 2018, pp. 1-4.

6. A. Mohamed, V. Salehi, T. Ma and O. Mohammed, "Real-Time Energy Management Algorithm for Plug-In Hybrid Electric Vehicle Charging Parks Involving Sustainable Energy," IEEE Transactions on Sustainable Energy, vol. 5, no. 2, pp. 577-586, Apr. 2014.

7. Y. Zheng, Z. Y. Dong, Y. Xu, K. Meng, J. H. Zhao and J. Qiu, "Electric Vehicle Battery Charging/Swap Stations in Distribution Systems: Comparison Study and Optimal Planning," in IEEE Transactions on Power Systems, vol. 29, no. 1, pp. 221-229, Jan. 2014.

8. K. Clement-Nyns, E. Haesen and J. Driesen, "The Impact of Charging Plug-In Hybrid Electric Vehicles on a Residential Distribution Grid," IEEE Transactions on Power Systems, vol. 25, no. 1, pp. 371-380, Feb. 2010.

9. Wei Yee Teoh and Chee Wei Tan, "An Overview of Islanding Detection Methods in Photovoltaic Systems", International Journal of Electrical, Computer, Energetic, Electronic and Communication Engineering, vol. 5, no. 10, 2011.

10. S.Sobri, S.Koohi-Kamali, and N.A.Rahim, "Solar photovoltaic generation forecasting methods: A review," Energy Conversion Management, vol.156, pp.459-497, Jan 2018

11. M. H. Amini, K. G. Boroojeni, T. Dragičević, A. Nejadpak, S. S Iyengar and F. Blaabjerg, "A comprehensive cloud-based real-time simulation framework for oblivious power routing in clusters of DC microgrids," IEEE Second International Conference on DC Microgrids (ICDCM), Nuremburg, 2017, pp. 270-273.

12. F. Luo et al., "Cloud-Based Information Infrastructure for Next-Generation Power Grid: Conception, Architecture, and Applications,", IEEE Transactions on Smart Grid, vol. 7, no. 4, pp. 1896-1912, July 2016.

13. Adegbohun, Feyijimi \& Jouanne, Annette \& Lee, Kwang. (2019) Autonomous Battery Swapping System and Methodologies of Electric Vehicles. Energies. 12. 667. 10.3390/en12040667.

14. S. Kaur, T. Kaur, R. Khanna and P. Singh, "A state of the art of DC microgrids for electric vehicle charging," 2017 4th International Conference on Signal Processing, Computing and Control (ISPCC), Solan, 2017, pp. 381-386.

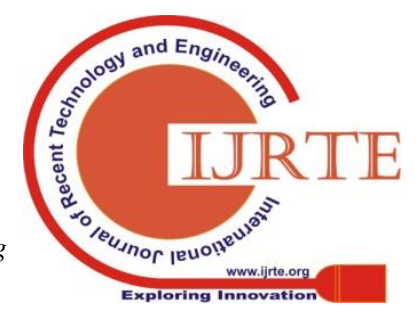


15. Victor George, Pradipkumar Dixit, Ayushi Priya, Deeksha Singh, Tanya Swaroop and Nikita D, "Data Communication between DC Microgrids for Real Time Converter Control" presentedat the Int. Conf. NCR, New Delhi, Computing, Power and Communication Technologies (GUCON 2019), Sept. 27-28, 2019.

16. Victor George, Deepak B, Shubham Kumar, Shobhit Kumar, Sindhu Reddy and Ashok S, "Design Aspects of the Future IoT Based On-Road Charging of Electric Vehicles" presentedat the Int. Conf. NCR, New Delhi, Computing, Power and Communication Technologies (GUCON 2019), Sept. 27-28, 2019.

\section{AUTHORS PROFILE}

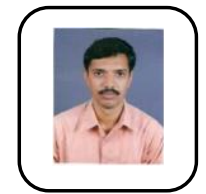

Victor George received MTech. Degree from Visvesvaraya Technological University, Belgaum. He is currently employed as an Assistant Professor, in Dept. of Electrical and Electronics Engineering, M.S. Ramaiah Institute of Technology, Bangalore, India. His special EV charging stations. field of interest includes energy systems, smart grid and

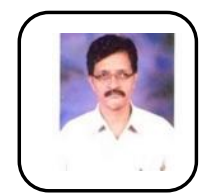

Dr. Pradipkumar Dixit received his MTech. from NITK Suratkal and $\mathrm{PhD}$ from VTU Belgaum. Presently he is working as a Professor in Electrical \& Electronics Engineering Department of MSRIT Bangalore. His areas of interest are high voltage engineering, outdoor insulation, lightning protection, electromagnetic compatibility, and electric power quality.

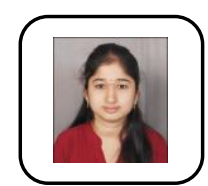

management.

Madhuri. Areceieved B.E degree in electrical and electronics engineering from M.S. Ramaiah Institute of Technology and currently working as an Associate Software Engineer in Robert Bosch Engineering \& Business Solutions Pvt. Ltd.. Her areas of interest include system automation, embedded applications and energy

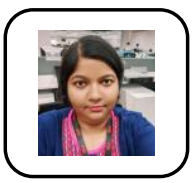

Sayantani Gupta receieved B.E degreein electrical and electronics engineering from M.S. Ramaiah Institute of Technology and currently working as Project Engineer in ABB India Ltd. Her areas of interest include system automation, smart grids and energy management

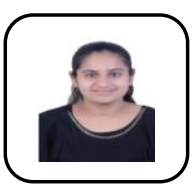

Vismayi. Vrecieved B.Tech degree in Electrical and Electronics engineering from Ramaiah Institute of Technology, Bangalore, affiliated to Visvesvaraya Technological University, Belgaum. She is currently working in GE Healthcare, Bangalore. Her areas of interest include renewable energy sources, Internet of Things and data analytics. 